\section{DANISH TRANSGENICS}

COPENHAGEN-Denmark is set to regulate, rather than ban, transgenic animals. And while this is a softening of the Danish position on transgenics, it seems likely that the regulations will nevertheless be fairly restrictive: the scientific use of transgenics may be closely evaluated case by case, and there is pressure to consider social and economic factors in the regulation of transgenic farm animals. This is likely to put Denmark into conflict with measures on transgenics being drafted by the European Commission (EC, Brussels).

The change in attitude was apparent from a recent "consensus conference," a uniquely Danish instrument of democracy, organized by the Teknologinaevnet in cooperation with the Parliamentary Committee of Research. The Teknologinaevnet is the Danish equivalent of the U.S. Congress's Office of Technology Assessment (Washington, DC). Consensus conferences, although they have no formal part in the legislative process, have profoundly influenced the content of Danish legislation. The documents that stem from the conferences have, for instance, shaped the 1987 public funding rules for biotechnology-which, for their part, excluded transgenic-animal funding-and the ongoing attempts to legislate the use of genetic tests for employment purposes. Kjeld Rahbaek Moeller, head of the Parliamentary Committee of Research, says that the time has now come for Denmark to regulate transgenic animals. "We have been in a waiting position for some years, unable to decide whether to ban or regulate. This conference tells us that regulation rather than a total ban will be appropriate," says Moeller.

\section{Consensus document}

Following previous formats, the recent consensus conference saw a group of experts-including advocacy-group representatives, scientists, and technical specialists_-present a range of opinions and evidence to a panel of 14 lay persons. After listening to and questioning the experts, the panel then drew up a document and sent it to the members of Parliament.

On transgenics, the consensus document has a number of recommendations:

-The experimental uses of transgenics should be decided on a case-by-case basis. While the lay panel felt that the Harvard mouse, for instance, would be acceptable since the target disease, cancer, is severe, not all disease models would be equally justified.

-Social, economic, and animal-health considerations should guide the regula- tion of transgenic animals for agricultural purposes. Added to general concerns for animal health in agriculture, the panel also questioned the need for more effective production in agriculture given European food overproduction.

The consensus document, in fact, addressed wider aspects of transgenic products. Although the panel was not against the use of foods containing or consisting of genetically modified organisms, it demanded obligatory labeling of all such products. It also explicitly expressed concern about the views from experts on the long-term safety of genetically engineered foodstuffs. On intellectual property, moreover, the panel endorsed the majority decision of the Parliament, taken in 1991, to oppose patenting of any life form.

Exactly how and when Denmark will proceed is unclear. But on transgenics, Moeller believes Denmark will follow the "Dutch model" of separate regulations for animal welfare on the one hand and animal experimentation on the other. Animal-welfare legislation, in fact, is currently passing through the Dutch Parliament's second chamber.

\section{EC proposal}

In parallel with Danish moves, the EC Directorate-General for Agriculture is circulating a draft proposal on the marketing and importation of transgenic animals. EC intends that the measure should go before the agriculture ministers from the 12 European Community countries before the end of this year. This has already created concern in Denmark that national authorities could not oppose transgenic animals under national law. Under the EC proposal, the commission would only have to "inform" member states about transgenic products and note their opinions. The final decision on approval would be taken by $\mathrm{EC}$, after consultation with its Standing Veterinary Committee, a panel of national veterinary experts. Some Danes are concerned that transgenic-animal products would thereby evade the more stringent procedures that apply under $90 / 220$, the European regulations for the release of genetically modified organisms into the environment.

The wording of the EC draft on transgenics is confusing in this regard. Leif Mortensen from the Danish Ministry of the Environment thinks that the transgenics directive would not prejudice 90/220. "However I am not totally sure that my reading of the text is correct," he says. -Thomas Breck

Thomas Breck is a freelance journalist in Copenhagen.
What to use in your

experiments --

PURE PEPTIDES

Call 1-800-966-3384

We also have:

- Fmoc AA resins

- AAA service

- Bulk synthesis

PEPTIDE TECHNOLOGIES

125 Michigan Ave. NE

Washington DC 20017

FAX 202-234-3385

Write in No. 424 on Reader Service Card

\section{AGARPET $^{\text {TM }}$}

\section{HIGH SPEED AGAR DISPENSER}

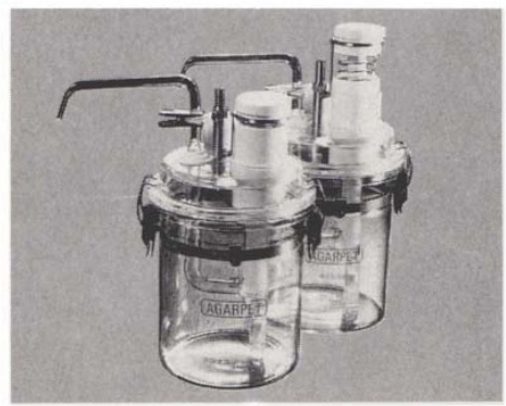

Agarpet $^{\mathrm{TM}}$, an adjustable dispenser, is an ideal tool for preparing agar plates easily and rapidly. It is autoclavable and designed to prevent contamination.

Features:

$*$ Volumetric Accuracy $< \pm 5 \%$

* Can be used to dispense agar into tubes as well.

* Two sizes available $(0 \sim 25 \mathrm{~m} l$ and $0 \sim 50$ $\mathrm{m} l$ dispensing ranges) and two types for the both sizes (with/without springs for pulling up the plungers).

\section{FUNAKOSHI CO., LTD.}

9-7 Hongo 2-chome, Bunkyo-ku, Tokyo, Japan. TEL: 81-3-5684-1622 FAX:81-3-5684-1233 TLX: J28489 FUNA 